\title{
Adieu BonJour: Getting Cognitive Possession of "Getting Cognitive Possession"
}

\section{Greg Hodes}

\section{Longwood Community College}

If I draw the attention of someone who is not a philosopher to a red patch and ask whether he sees something red will say that he does. If I explain to him the difference between red objects and red sensa, between red patches which are alleged to exist not merely in one's mind but in the world and red patches about which no such commitment is made, he will say that he certainly sees at least a red sensum. Asked how he knows he is seeing it, he will respond with a puzzled stare. If I insist on an answer he will say, in effect, that he understands the meaning of 'I (he himself) am (is) seeing a red patch' and understands the difference between seeing a red object and seeing a red sensum, but that he continues to have at least a red sensum in his visual consciousness and that that is sufficient to justify his belief that he is seeing it. If pressed further, he will want to know what more I could want, what further questions remain to be settled.

In the first part of this paper I argue that Lawrence BonJour's coherence theory of how such empirical knowledge is acquired does not work. In the second part I argue that our man-in-the-street has neglected to mention a crucial intellectual operation which has in fact occurred-an operation quite different from anything proposed by BonJour-and that when this operation is identified and made explicit his account will prove to be correct. The argument will be neither foundationalist, in the usual sense of that term, nor coherentist. Nor will it appeal to language, "common sense," or pragmatic values.

\section{BonJour's Coherence Theory}

In an important and much discussed book, BonJour argues that:

There are no basic empirical beliefs . . . whose justification does not depend on that of any further belief. [BonJour, p. 32] 
It follows that the actual presence in or to one's consciousness of a datum of sense does not suffice to justify one's belief that that is the case. Since, as we shall see, on BonJour's theory the sensum itself plays no role at all in justifying the belief in question, the man-in-the-street account given above would be not merely incomplete but wrong from the start.

It is important to see at the outset just how counter-intuitive BonJour's account of first person empirical knowledge is.

He distinguishes sharply between the cause or origin of one's empirical belief and its justification. The cause or origin of an empirical belief may be extratheoretical (which for BonJour is not necessarily the same as extra-mental, as we shall see), but one's justification for believing it is to be found only in the coherence of that belief with other beliefs together with the a priori "theorem" that such coherence implies extratheoretical causation and, therefore, truth. Where the problem is to determine whether a sensum present to one's consciousness is or represents an extra-mental object, this cause-justification distinction may seem appropriate. For we have the problem just because we do not have, or cannot know we have, direct perceptual access to extra-mental objects or to the extra-mentality of sensa of which we are directly aware (A mental red patch looks just like an extra-mental red patch).

But where the issue is whether one is perceiving the sensum which he is in fact perceiving, the result seems very odd indeed. For since BonJour holds that justification by coherence with other beliefs is approximated only in the long run and is only probable, it follows that although in the short run one might be more justified than not in believing one is seeing a red patch, in the long run one may be more justified than not in believing one was seeing a green patch-although all along one has only been hearing a siren-like noise and having no visual experience at all!

It is not easy to see how to avoid this result if the sensum itself plays no part in justifying one's beliefs about it. And because inference to an extra-mental object would, on BonJour's account, require a prior inference that there is a sensum present in or to one's consciousness, any implausibility attaching to the latter procedure will attach to the former inference as well. BonJour's separation of the origin of a belief from its justification and his view that basic 
beliefs can be justified only through other beliefs lead to this result. But he need not-and perhaps would not-reject either view for this reason; he may simply choose to live with the near paradox they imply. Others will find such a result an unacceptable.

I agree that the mere perceptual presence of a datum of sense does not by itself suffice to justify the claim that one is having it, and in part II I offer a more plausible theory of what else is needed in addition to the sensum.

BonJour's reason for holding that a basic empirical belief can be justified only by other beliefs is as follows:

...I will assume that such a belief is always the belief, linguistically formulable only in expressive language ... that a certain specific content is present, for example that I seem to see something red. If this belief is true .... then it must also be the case, second, that a red element [i.e., sensum] is present in the experience of the person in question. But these two elements are not enough. The [experiential content] must be grasped or apprehended .... Is [this apprehension] cognitive or non-cognitive, judgmental or non-judgmental? ... If the apprehension of the given is cognitive or judgmental ... [then it is] difficult or impossible to see why it does not itself require justification. If it is non-judgmental and non-cognitive ... then there is no apparent way for that apprehension to provide any sort of epistemic justification. [BonJour, p. 74-75.]

By "expressive language" BonJour means "language that neither asserts objective reality of what appears nor denies any, [confining] itself to the content of presentation itself." I will continue to refer to such items as 'sensa'. Thus his argument applies equally to immanent ("subjective") and non-immanent ("objective") sensa. It is important to be clear about this. The problem for BonJour is not, or not only, how we can know that such sensa belong to or represent an extra-mental object, but how we can justify our belief 
that we are experiencing them, regardless of their status as mental or extra-mental.

Notice also that BonJour is not challenging the correspondence theory of truth: I seem to be seeing something red is true only "if such an element is present to my consciousness." The issue is how such beliefs are justified, not what it is for them to be true. The reason BonJour sees "no apparent way" for the sensum to justify the belief that one is experiencing it is that he sees the sensum as epistemically incommensurate with the propositional nature of belief. ${ }^{1}$

How after all can a red experiential element fail to be logically distinct from the cognitive apprehension that such an element is present? The latter, unlike the former is propositionally formed, capable of being true or false, and capable of serving as the premise of an inference; whereas the former, unlike the latter, is literally red (in the appropriate sense). How can two things as different from this fail to be distinct? [BonJour, p. 76]

For BonJour the fact that the bare experience of sensum is "logically distinct" from - not epistemically the same sort of thing asthe cognitive apprehension of it means that the sensum is incapable of implying the truth of the belief and therefore incapable of justifying it. Because the sensum is not a proposition it is simply irrelevant to what BonJour sees as the strictly propositional operations of justifying beliefs. In much the same spirit that Hume does not allow an ought to be derived from an is, BonJour does not

\footnotetext{
1 The expression 'epistemically incommensurate' is mine, not BonJour's. But if a sensum, just as it is, can be the sort of thing which makes the proposition asserting its presence in consciousness true, why cannot the same sensum, just as it is be the sort of thing which can justify that proposition? I suspect there may a good reason for this asymmetry, though space does not permit adequate discussion here. Briefly, truth arises from the conformity of the mind to the object to be known, but justification seems arise from the conformity of cognitive procedure to the needs and norms of intellectual curiosity. This account of justification is discussed in the text (II.2).
} 
allow justification to be derived from a bare perception, but only from a fact of perception which is known to the subject to be a fact and is itself, therefore, propositional. Hence the vicious regress.

\section{I.1. Spontaneous Empirical Beliefs}

According to BonJour, one find one's self holding empirical beliefs which are not derived from any previous beliefs: for example, the belief that one is seeing a red patch. These "spontaneous empirical beliefs" (or SEBs) are said to provide candidates, but only candidates, for extratheoretic input (ETI), an input which he, unlike other coherence theorists, holds to be indispensable. Again it is essential to note that for BonJour 'extratheoretic' means non-conceptual, not or not necessarily, extra-mental. It is the radical claim that we are not justified in believing we are seeing a red patch merely because we are seeing it which, in my view, makes his theory interesting.

These beliefs are to be justified, not by reference to the sensum itself, but by their coherence with other beliefs, including beliefs of the same kind as the belief in question, and ultimately by the $a$ priori theorem that extratheoretic causation is the best explanation of such coherence. Extratheoretic causation, in turn, implies truth. He sees, of course, that the attempt to justify the coherence judgments themselves by an appeal to further coherence judgments leads to a vicious regress; but he declines to explain how such judgments are justified, candidly acknowledging that his account is, to that extent, incomplete.

Now, it seems obvious that we can and do have SEBs. But suppose that we have read BonJour and, therefore, realize that our SEBs stand in need of justification-may, for all their force and spontaneity, be false? Do we now have such spontaneous beliefs or don't we? Surely, one cannot have it both ways. One cannot continue to hold a belief at the very same epistemic instant that she realizes it requires justification and, therefore, that she does not know whether it is true-after all, a belief is a genuine conviction. It would seem that BonJour's theory makes an SEB a candidate for input, in part, because we believe it and a candidate for justification because we don't believe it. 
But, surely, raising the issue of justification changes an ungrounded "belief" into an hypothesis, and resolving the issue of justification promotes an hypothesis to a justified true belief. Justification does not change a belief we do not really believe into one we really do believe.

It follows that there are no SEBs of one's own available to one's self after the issue of their justification has arisen. For to see the need for such justification is to see that one ought not to have held the belief in the first place. As a philosopher interested in epistemology one is in just this position and cannot help being in it. One might recall that one did have such a justification-indifferent "belief," although one no longer has it; but then one would have to see the previous "belief," not exactly as a mistake, but, as argue below (II.4), as an epistemic misfire, a lapse from the status of fully competent cognitional player, But if an alleged SEB has no epistemic credibility, why, apart from its' being underived from intratheoretic items, should it be any better a candidate for extratheoretical causation than any other vivid experience?

\section{I.2. Naturalized or Normative Epistemology?}

The appeal to SEBs conflates normative and naturalistic theories of cognition. We are told that when one is experiencing a red patch the belief that one is experiencing it is "forced upon him" but that this compulsion does not justify the belief. [BonJour, p. 1 17.] But can an empirical belief be caused in a rational subject in a naturalistic or quasi-naturalistic way by items in the extratheoretic world? If a belief can be said to be "forced" on a rational subject 'when he is being fully rational, the compulsion must surely be a rationally normative one, essentially and intimately connected with the sensum, but not the sort compulsion with which extreme heat causes pain or red stage lighting makes things appear reddish.

Similarly, the red patch cannot, properly speaking, be an efficient cause of the truth of the belief that one is seeing it. (As far as I know, BonJour doesn't says that it can.) The sensum makes the belief about it true just by being what it is affirmed to be: a red patch present in my consciousness. That an item is such-and-such, and thus that the hypothesis that it is a such-and-such is true, may 
be perhaps inferred from its effects; but the only assertion that the item's causal efficacy can make true is the assertion that it has such efficacy. Even in this case the truth relation does not consist of any sort of efficient causality.

What is naturalistically "forced" upon a rational subject in this way, it seems to me, is the sensum, not any understanding of it, not the fact that it constrains a theory, and not the belief or even the hypothesis that one is perceiving it. BonJour sees that the sort of belief we really want is properly normative-that is why he thinks it must be justified through coherence. But at the same time he clings to a non-normative view of belief, perhaps in the hope that it will help establish the possibility of a causal, existential hook-up with the extratheoretic. (BonJour makes this connection primarily through the a prior "theorem" attributing coherence to extratheoretic causation. I have no objection to the a priori theorem, at least none I will develop in this paper.)

\section{I.3. Will Spontaneous Empirical Hypotheses Serve as Candidates for Extratheoretic Input?}

Without SEBs we are left with spontaneous empirical hypotheses (SEHs). These would indeed eliminate the need to be in two epistemically incompatible places at once. But now there are other serious difficulties, as Bonjour is very much aware. (BonJour, pp. 107-8, 149-53). Seeing in some detail just why SEHs will not serve will help the reader follow the account of empirical knowledge developed in Part II.

Obviously, SEHs make very implausible candidates for extratheoretical input - that is one of the reason BonJour thinks he needs SEBs. To say that the mere occurrence of an empirical hypothesis constitutes grounds for thinking it a candidate for supplying such input is to lose the very notion of an hypothesis. The fact that such an hypotheses is underived from other hypotheses or belief comes a little nearer the mark, although I confess I do not know in what sense of 'derive' one might derive an hypothesis from a belief.

(1) Note that the hypothetical status of proposition consists in its not being known by the subject to be true, not in its not being 
true. Thus those who, like BonJour, espouse a causal theory of truth can also hold that an empirical proposition may function as an hypothesis for the subject even though it is in fact extratheoretically caused, provided the subject does not know that it is so caused. But that an SEH is a candidate for ETI must, on BonJour's theory, be known prior to learning, via coherence, that it is extratheoretically caused; so its actually being so caused can do nothing to establish the SEH as a candidate for such input.

(2) We have seen that one cannot hold both normative and naturalistic epistemologies about belief. Similar normative difficulties would arise with a causal theory of hypotheses, for an empirical hypothesis is an intelligent and intelligible characterization of the sensum. On the one hand, its normativity cannot be that of a rational belief, since even a wrong hypothesis may be perfectly intelligible. On the other hand, its intelligibility is quite different from the perceptual awareness imposed by a sensum and, as we have seen, cannot be the result of having had certain efficient causes. The function of any hypothesis is to move the cognitional project from the level of sense to the level of intelligibility, and it would seem that something more than mere sense input is need to do this.

(3) There is the obvious difficulty that the number and range of empirical hypotheses are largely a function of human inventiveness and time. Thus the problems of assessing coherence and showing that there could not be more than one complete and coherent theory become very much more difficult. [BonJour, pp. 107-8, 14953]

Although I will speak of spontaneous empirical beliefs (SEBs) in what follows, I will often mention spontaneous empirical hypotheses (SEHs) as well - just to remind the reader that there are no such things as SEBs available to him as an epistemologist and to note that the argument then in progress works for both SEHs as well.

\section{I.4. Extratheoretic Input, Justification, and Sensa}

I said above that on BonJour's theory the presence or absence of the accompanying sensum is quite irrelevant to the justification of one's belief that one is experiencing it. It is also irrelevant to the 
identification of SEBs (or SEHs) as a candidates for ETI. It is important to see in detail why both of these results follow.

BonJour insists that there must be at least the possibility of extratheoretic input, and he thinks that as candidates for ETI SEBs provide this possibility. But the grounds for believing that SEBs (or SEHs) are candidates for this role cannot be any knowledge that they in fact are, or probably are, extratheoretically caused. For given BonJour's view that such causality implies truth, this knowledge would provide some justification, however slight, for our thinking they are true-a justification which has nothing to do with coherence. For this reason, BonJour makes candidacy for ETI depend only on an SEB's not being derived from any other belief and the fact that we strongly (but not yet justifiably) believe it. But neither the fact that SEBs are not derived from other beliefs nor the fact that we "believe" them tells us anything about whether such beliefs actually are so caused, as BonJour himself insist.

I have just distinguished the claim that an SEB (or SEH) might (or might not) be extratheoretically caused from the "theorem" that any individual SEB or, more accurately, any coherent set of such SEBs (or hypotheses) probably is so caused and, therefore, true. Now it is the "theorem" alone which provides positive grounds for inferring ETI, that is, causation of the SEB by the sensum, from its coherence with other beliefs; and the grounds for holding the theorem to be true are entirely a priori, as BonJour also insists.

The fact that the theorem is supposed to apply only to SEBs might be thought to supply an a posteriori component to justification, but no help is to be found in that quarter. For, since any SEB might turn out to be false, it might also turn out that there was never any sensum, and hence never any extratheoretic cause of the belief, to start with-the fact that one was perceiving it notwithstanding. All that counts in an SEB is the fact that such a belief might have extratheoretical causes and that one spontaneously "believes" that it does. To repeat, the fact that it is an SEB tells us nothing about whether it is actually so caused. For the same reason, the fact that an underived belief is extratheoretically caused can play no part in our identifying it as a candidate for ETI, although its being underived from other beliefs (or hypotheses) can. 
Thus, both the status of a belief (or SEH) that one is experiencing a sensum as a candidate for ETI and the justification of that belief are completely independent of the actual presence or absence of the sensum.

Obviously, this result cannot be blocked by arguing that one could not have the SEB that one was experiencing the sensum unless one were in fact experiencing it; for this would be a retreat either to a correspondence or to a causal (externalist) theory of justification, both of which BonJour of course rejects.

If BonJour's theory allows for extratheoretical input, it does not do so through its account of justification, but through it causal theory of truth. I have argued above (I.2) that an extratheoretic event is not, merely as an efficient cause, sufficient to bring about either a belief or an hypothesis, or their truth, because these are irreducibly normative in a way that a natural, efficient causes is not.

\section{I.5. The "Doxastic Presumption"}

Professor BonJour is very much concerned with how one can know that one has an SEB and how one can know that he holds his total set of beliefs. These two problems arise because, according to BonJour, having an SEB or a set of them is itself an empirical event, knowledge of which is essential to the application of the coherence theory of empirical knowledge being proposed. [BonJour, 80-1]. The "doxastic presumption" (DP) is offered as the solution to both these alleged difficulties.

DP is the claim that to ask whether a belief or set of beliefs is justified is to presuppose that we have the beliefs. BonJour sees that DP cannot function as a premise: "for to apply it . . . would require ... the further premise that $I$ do in fact have such specific beliefs, and the justification of these further premises would obviously be just as problematic as before." His solution is to view DP as a "practice" in something like Wittgenstein's sense.

But one philosopher's "practice" may be another philosopher's ducked issue. One cannot simply rely on DP as a practice; one must be prepared to show that it is a justified practice, and BonJour does in fact do a convincing job of justifying it. But if there is a 
problem about knowing that we hold our SEBs (or SEHs), will there not also be a problem about knowing that we believe DP, so that DP would have to be applied to itself? Not for BonJour. The difficulty DP is intended to remedy arises in connection with SEBs, and DP itself is, near enough, analytic. Thus he need not deal with this difficulty at all; for, it will be recalled, BonJour declines to offer any account of non-empirical knowledge.

But if knowing that one holds an SEB (or SEH) were a genuine problem, it would, it seems to me, be very necessary for BonJour to explain why it is not a problem for non-empirical beliefs (or hypotheses) as well, and such an explanation does not readily present itself.

Fortunately, however, there isn't any problem about knowing that we hold either kind of belief. The requirement that one know, that is, have a justified true belief (or hypothesis) that one is having a belief (or hypothesis) surely entails per se a vicious regress. In general it cannot be a necessary condition for justifying an empirical belief that one first acquire a justified empirical belief. In the case at hand, it cannot be a necessary condition for the justification of a belief $(p)$ or an hypothesis $(h)$ that one have a justified true belief that one believes (p) or hypothesizes (h). As we shall see in a moment, what is necessary in order to move on to the issue of justification is just that one consciously hold (p) or hypothesize (h).

It may be thought that such knowledge is needed for the global assessment of coherence which BonJour's theory requires. But neither the question of what beliefs we hold but are not presently conscious of nor the question of what beliefs we are now holding consciously requires for its resolution that we form a justified true belief. The first requires only that we recall the belief and continue to hold it; the second, as already noted, requires only that we consciously hold the belief at the time we seek to justify it. I argue for this analysis below (I.6).

The moral is not that the doxastic presumption is wrong-I think it is plainly right-but that it is not needed. 


\section{I.6. The Doxastic Presumption and Constitutive Consciousness}

We have just seen (I.5) that it cannot be a necessary condition for acquiring a justified true belief that we first acquire a justified true belief. But in order to make another, more interesting point about the allege need for DP, it will be necessary to distinguish the various kinds and stages of "taking cognitive possession."

First, experiencing a sensum, entertaining an hypothesis about, or having an insight into, that sensum, and forming a justified judgment that that hypothesis or insight is or is not correct are all acts of "taking cognitive possession:" that is, they are all conscious acts and they are all elements of empirical knowledge. But they obviously differ in very significant ways, are experienced as different kinds of consciousness and serve different but complementary functions. It requires no intelligence to have a percept; it does require intelligence to formulate an hypothesis about it, wonder whether the hypothesis is true, and determine that it is or is not. To talk of "taking cognitive possession" as though it consisted only of its final consummation in a justified judgment, or to speak vaguely about some epistemic act or other, blurs the relevant context and sets the stage for more serious confusions.

Second, it is not necessary to know (have a justified true belief or hypothesis) that one is holding a belief or hypothesis in order to raise and answer the question of its truth. It is one thing to know, believe, or hypothesize that, say, snow is white and another thing to know that one knows, believes or hypothesizes that it is. The first level acts of cognition do not require the second level acts of cognition, even if justification is by coherence. And the second level acts would not make us any more knowing or believing about the color of snow or any more understanding of our hypothesis about it. This is obvious from the fact that we could not know, believe, or hypothesize that we know, believe, or hypothesize that snow is white unless we already knew, believed, or hypothesized that it is, for there would as yet be no first level cognitional acts to know, believe, or hypothesize about. The doxastic presumption suggests this point but does not focus on it in quite the right way, 
and the doctrine of spontaneous empirical beliefs buries it in muddle.

Believing or hypothesizing about the color of snow matures into knowledge about the color of snow; it does not mature into knowledge that one is having the conscious experience of believing, hypothesizing or knowing about the color of snow, for none of these were the content of the belief or hypothesis.

On the other hand, such second level cognitions, if they occur, are genuinely new acts of knowing. To ask why an act of believing that snow is white is an act of believing and not an act of hypothesizing, is to learn some epistemology, not to learn a bit of meteorology. Similarly, to know that snow is white is to have a justified true belief or hypothesis about snow; but to know that one has such knowledge is to know, not only about snow, but about one's cognitional acts.

It follows that the proposition we been focusing on-I am seeing a red patch does not give us the first level hypothesis we want. It poses a second level question about our experiencing, whereas what we want to know is just whether there is a red patch; that is, we want to ask this without also asking whether one is having the experience of seeing it. I have used the expression until know to avoid distracting complications.

There is no problem with the distinction, but the language resists expressing it both adequately and briefly. There is a red patch will serve, provided we understand, without proposing or affirming, that the patch is present in or to the consciousness of the subject considering the proposition; that is, the reference to someone's conscious experience serves to identify or describe the proposition we wish to consider but is not part of that proposition (Compare: 'The man in the gray suit is drinking scotch'. The sartorial situation is not part of the proposition being asserted, since the proposition would remain true even if the suit were brown.) With this understanding I will be using There is a red patch from this point on.

Third, doesn't raising the issue of whether we are justified in holding a belief or in affirming an hypothesis require us (a) in some sense to take "cognitive possession" of the belief or hypothesis and of the fact that it is occurring to us, and (b) won't such taking cognitive possession require justification and thus launch a vicious 
regress? This is, after all, BonJour's main objection to foundationalism. The answer to (a) is yes; the answer to (b) is no.

(a) The act of forming a belief or inventing an hypothesis is an empirical event which is already conscious, and its content is already a "taking cognitive possession" of a certain preliminary and incomplete way. Only in the sense in which believing or hypothesizing is already a conscious act is it required to have "cognitive possession of" one's believing or hypothesizing (I shall explain the scare quotes around 'of' in a moment). And only in the sense that the belief or hypothesis itself is already the content of such act is it required for us to have "cognitive possession" of it.

If the belief or hypothesis is (somehow) justified we will also be in cognitive possession of the fact, for example, that snow is white. But justification does not require a second act of knowing, the object of which is the believing or hypothesizing (or the belief or hypothesis). It requires the addition of another kind of conscious, cognitional act to the believing or hypothesizing: an act of inquiring about and verifying its truth. This is a further development in the cognitional project of which the believing or hypothesizing was a preliminary stage. The point of these further operations is not to know whether our presently conscious belief or hypothesis has occurred, but to determine whether or not it is true. Knowing, that is, having a justified true hypothesis or belief, that we are believing or hypothesizing would do nothing to aid in this project and would lead to a vicious regress, as was shown above.

Of course one might inquire whether one is believing, hypothesizing or experiencing (a very different inquiry from the one to which the original believing, hypothesizing or experiencing was directed), and then these would become objects of consciousness, as distinct from the original conscious acts themselves (hence the scare quotes around 'of' two paragraphs back). This distinction is crucial. There is a tendency to think of consciousness as though it itself were an object of consciousness (so self-consciousness becomes a kind of looking at one's consciousness looking at itself). But this is like saying that power of sight consists of looking at one's eyes. If the eyes are blind they will see neither themselves nor anything else, and their not being blind just is their being visually conscious regardless of what they happen to be looking at. 
In the same way, experiencing, inquiring, hypothesizing, catching on, believing, justifying are all intrinsically conscious; they do not require to be made conscious by becoming objects or contents of consciousness. Consciousness, albeit of different kinds, is constitutive of such acts in a way that it is not constitutive of their objects or contents, whose status as conscious is derived from the consciousness ("consciousing") which is epistemically prior.

For this reason objects or contents of consciousness, as such, are conscious neither of themselves nor of anything else, while what is intrinsically and constitutive conscious is conscious "of" itself non-dualistically, that is, simply by being the consciousness ("consciousing") it is; and this is a necessary condition for its being conscious of anything else. On the other hand (and more plainly), consciousness is not in any way constitutive of the operation of one's pancreas, and the operation of one's pancreas does not become conscious in the epistemically prior sense of 'consciousness' when one thinks about it. (Immanent sensa, concepts, beliefs, and hypotheses occupy an intermediate position between what is intrinsically, constitutively conscious and what is not conscious at all; we are inclined to say that they exist only as objects of or in consciousness.

What is required for empirical knowledge, then, is that we have been believing or hypothesizing about data and that we are subsequently successful (in a way yet to be discussed) in justifying that belief or hypothesis. To think that the successive stages in empirical knowing have each to be known in order for the act of knowing to occur is to miss the way these different cognitional operationsthese different stages of "taking cognitive possession"-fit together to constitute knowledge. Before there can be any question of grounds for a judgment of truth, there must be an hypothesis, belief, or insight about which to judge, and these will be about some content of experience-data, in the broad sense (For this sense of 'data' see below (I.7.) None of these by itself is an act of knowing and, although each is the content of a distinct kind of consciousness, none of them need be known, that is, need be the content of a justified true belief or hypothesis.

On this view, knowing is not a complex of acts of knowing; it is a functional integration of differentiated conscious acts and ob- 
jects of such acts, culminating (in a way yet to be discussed) in a justified hypothesis, insight, or belief. Every such set of epistemic acts-including those which result in correct epistemological theories-is an empirical event in BonJour's sense, that is, something that happens. Nevertheless, it is epistemically complete; it does not require to be subsumed under some other epistemic event.

So it is important to be clear about which inquiry one is referring to, which stage in the cognitional process one is talking about, and whether one is talking about a conscious act or the object of such an act. If I am interested in knowing whether snow is white, I go on to investigate the evidence (foundationalist or otherwise) relevant to the color of snow; if I am asking whether I am experiencing the white, cold, fluffy stuff descending from the sky, I must also go on to investigate the evidence for my performing a certain kind of conscious act. This second level experiencing, by which the original, first level experiencing is made an object of consciousness (it was already conscious in the other sense), does not by itself constitute one's knowing (having a justified true hypothesis or belief) that one is having the original experience, any more than sensing the red patch means that one knows there is a red patch.

(b) It is should now evident that there need be no problem about justifying one's belief or hypothesis that one is having a belief or hypothesis. No such second level knowledge, and therefore no such second level belief or hypothesis, is required so long as one is only interested in justifying the first level belief or hypothesis. In the same way, to inquire whether a set of beliefs or hypotheses is coherent is to inquire about the logical relations among the beliefs or hypotheses, not about whether one is having them. Below (II.2) I show how these the components of cognition can be known-when it is necessary to know them-without a vicious regress.

\section{I.7. Sensa and Propositions As Data}

Formulating the problem narrowly in terms of sensa is misleading. The crucial difficulty, it seems to me, is the epistemic move from any content or object of consciousness which is not yet understood or fully understood, to the understanding and knowing of 
that content. It is the present opacity to intelligence of an item in consciousness (or of some feature of it) which is relevant, not the fact that the item happens to be an object of sense. Now, to ask whether our entire set of beliefs (or hypotheses) is ("approximately") coherent may imply that we hold those beliefs (or hypotheses), but it does not tell us whether they are in fact coherent. To know this, we need some sort of foundationalism. It is, I suspect, because BonJour sees this need in the case of justifying coherence judgments that he declines to explain how they are justified. But he does not see any parallel possibility in the case of firstlevel empirical judgment [BonJour, pp. 104-5.]

There is a certain "picture" of how knowing occurs at work here. On this view, to put it rather epigrammatically, sensa are for looking at, touching, hearing, smelling, etc., and concepts (alternately, language) are for understanding. There is no possibility of deriving concepts or propositions from sensa by an act of understanding ("gaining cognitive possession") which makes the sensa intelligible and known. On the other hand, one can "take cognitive possession" of the coherence of one's beliefs or hypotheses, without any further operation of intelligence, merely by taking a conceptual "look" at them collectively, because they are propositions and hence already intelligible.

But it seems obvious that a further operation of intelligence is needed in order to know whether one's beliefs are coherent; for, again, it is one thing to have all one's beliefs in mind (either implicitly or explicitly) and quite another to evaluate their coherence. The unrelated beliefs (or hypotheses) are, in my view, merely data for such additional understanding, just as sensa are merely data for whatever understanding of them we can attain. By 'data' in this extended sense I mean whatever one is conscious of prior to making it an object of intellectual inquiry and understanding. So if there is a problem with justification in "taking cognitive possession" of the sensum, there will be the same problem with taking cognitive possession of the coherence or incoherence of our beliefs (and of the conclusions that follow from our premises). BonJour sees that intelligent operation on the beliefs themselves is required to grasp their coherence; he does not see that the same sort of act is needed to grasp an empirical fact. 
Further, if one can have insights into propositional data without launching a vicious regress, then why not into data of sense? BonJour observes, almost as though it settled the issue, that the proposition I am seeing a red patch does not "look like" a red patch [BonJour, pp. 76]. But neither does a bundle of unrelated beliefs (or hypotheses) "look conceptually" like the proposition These beliefs or hypotheses) are a coherent. It is true that the propositions taken separately are already understood (although even considered individually few are likely to be understood exhaustively), while the sensa merely as experienced are not understood at all; but is this difference sufficient to make the as yet unknown relations among the propositions open to direct insight while sensa remain forever closed to it? Is the crucial distinction the one between data of sense and propositional data, as BonJour seems to hold, or the one between data of any type and the understanding of the data? Against BonJour's view it may be pointed out that we do not, in the most fundamental case, infer one proposition from another by means of other propositions. We do so by the direct insight that they are related in a certain way.

Thus far nothing has been said about how the product of either type of insight is justified. Both the act of direct understanding and its justification will be discussed in Part II. But it may be noted here that this possibility alters the issue. The problem will no longer be how to justify an SEB (or SEH) by means of unintelligible raw data of sense, but how to justify an act of understanding which purports to make the raw data intelligible.

\section{I.8. Summary of Part I}

I suggested that understanding data of sense does not differ radically from the understanding of the ensemble of propositional data required for a coherence judgment. I proposed (a possible, unresolved difficulty notwithstanding) that in both cases there is an intrinsic but latent intelligibility to be grasped. If such an insight can produce justified true belief in one case, as BonJour admits, it would seem can do so in the other, as well.

I argued that it is not possible to hold a belief at the same epistemic moment that one is aware that it is in need of justifica- 
tion and, therefore, that there can be no SEBs for a rational subject. The problem thus became one of justifying an empirical hypothesis through its coherence with other empirical hypotheses, I considerable more daunting project.

Once the naturalistic epistemology implicit in the theory of extratheoretically caused spontaneous empirical beliefs was set aside, it also became clear why on BonJour's theory the actual presence of a sensum in one's consciousness plays no role at all in the justification, as distinct from the truth, of the assertion that one is experiencing it. For the fact that there has actually been such input becomes epistemically available only as a consequence of justification. For the same reason the sensum can play no role in our identifying an SEB as a candidate for input. Nor does the sensum play any part in constituting a belief as a spontaneous empirical belief, for the belief that we are experiencing a sensum might turn out to be false and, therefore, not to have been caused by a sensum. I argue that the sensum cannot be an efficient cause of a belief, hypothesis, or their truth, for these are all normative in a way that cannot be produced by an efficient cause.

A more detailed analysis of the operations constitutive of knowing showed that the "doxastic presumption" allegedly required in order to know that we are in fact experiencing an empirical belief is unnecessary. Further, I argued that the requirement that we know-have a justified true belief - that we hold an empirical belief (or any belief or hypothesis) in order to justify it is per se viciously circular.

In fact Professor BonJour's ingenious and painstakingly argued theory does not adequately address the fundamental problem in justifying empirical beliefs or hypotheses, not only because, as he himself acknowledges, no account is given of how coherence judgments are justified, but, surprisingly, because justification lies in an entirely different quarter. 


\section{A Theory of Empirical Knowledge ${ }^{2}$}

I do not think the problem which motivates BonJour's theory can be dismissed or that it is solved by the usual foundationalist argument that such beliefs are justified simply by one's being conscious of the sensum. Why should a process of inquiring, understanding, hypothesizing, weighing the evidence be essential for some kinds of empirical knowledge but play no part at all in other kinds. If merely gaping at the planets does not suffice teach us the law of inverse squares, why should the same perceptual act, taken all by itself, constitute knowing that we are having such experiences, however banal that knowledge may be? But if acts of understanding and judgment are required, then, as BonJour rightly insists, so is justification; and if mere perception was not sufficient for justification in the first instance, neither will it be sufficient to justify the result of these further intellectual operations. What follows is a account of how empirical knowledge is attained.

2 The theory of cognition presented here is, with two modifications, that of B.J.F. Lonergan. One modification is that, where Lonergan writes as though justification consisted of a second level insight that there are no further relevant questions remaining to be addressed by the first level insight [Lonergan, pp. 308-312], I argue that the constitutively conscious satisfaction of the first level curiosity by the first level insight constitutes justification. I prefer this view because I do not see how a justifying insight ("judgment") could itself escape the need for justification, or what would justify it if not the first level satisfaction together with an additional second level satisfaction of the second level query. Such a second level yes/no insight is attractive because it would provide a crisp. explicit closure, but 1 cannot convince myself that it is necessary or sufficient. The intended result is the same on either view, since the epistemic possibility of error, doubt, or revision depends upon there being further unresolved questions or issues.

The other modification is my theory of error, which is not given explicitly by Lonergan but with which I think he would agree. For a lucid and relatively brief introduction to Lonergan, see Hugo Meynell's An Introduction to the Philosophy of Bernard Lomergan, 2nd Ed; University of Toronto Press, 1991. 
II.1. Getting Cognitive Possession of the Data as Experiencing, Inquiring and Catching on

If seeing a red patch were knowing there is a red patch, the question of justification would not arise, and knowing in this case would require no intelligence-not just very little intelligence, but none at all. In the same way, if knowing that a set of statements was coherent were merely to have understood each statement, then no further act of intelligence would be needed to grasp their coherence or incoherence and the question of justification would not arise. And, to repeat, if acts of intelligence are required, then they must be justified. But we have seen that they cannot be justified by further judgments of coherence or by introducing "practices" which are not themselves justified. So if our problem has a solution it must at some point be possible to acquire justified true beliefs by operations performed on the data itself, where "data" means anything in consciousness which is not yet known or fully known. Here I focus on the operation of intelligence; in the next section I face squarely the problem of how the content of such an act of intelligence is justified as a correct understanding of the data.

Recall that the presence in consciousness of a red patch could not, given the rest of BonJour's account, play any role in justifying the belief (or hypothesis) that one was perceiving it (I.6). But consider how BonJour must have arrived at his epistemological convictions. Would his theory be plausible even to himself if it had been formulated without his having had any prior experience whatever of knowing or trying to know? Does one merely hypothesize that empirical knowing is such and such and go on to evaluate the hypothesis, without reference, in either operation, to any experience of knowing or trying to know this or that? If one did succeed in justifying an epistemological hypothesis without such input, the resulting knowledge would be true of the experiences of knowing or trying to know without in any way being derived firom those experiences. But acts of first level knowing or trying to know play the same role in working out epistemological theories as do sensa in first level cognitions. Of course, indirect justification could occur in a particular case by inference from other empirical knowledge. But if data were always irrelevant to justification and if 
BonJour's version of coherence theory doesn't work, how-except by recourse to an viciously regressive coherence theory cut off from all extratheoretical input-would any knowledge be possible, either knowledge of our sense experiences or knowledge of how we acquire such knowledge?

There is a question of experienced cognition fact here. Has the reader ever gotten curious about some data, puzzled over it, and caught on to something which struck her as intrinsic to the data? Was the curiosity about, directed to, the data? Were the formulation of the puzzle and the insight into its solution directly related to her curiosity and the object of that curiosity? Was the correctness of the insight always verified independently of that data?

Consider a sensum which, although you do not at first realize it, is in fact a geometrical construction drawn to prove a certain theorem. When it dawns on you that a theorem is being proved, what theorem it is, and why the proof works, it will, I suggest, strike you as patently at odds with the conscious epistemic acts you have just been performing to insist either that the increment in knowledge drew in no way at all on the experience or that the knowledge was nothing more than the experience. Would you or would you not able to show why the insight was correct (or at least cause someone else to have it) in terms of the data itself?

Consider the analogous example of showing, in terms of the propositions themselves, that a set of proposition is coherent. Can such a judgment only be made by checking its coherence with hypotheses or beliefs other than those in whose logical relations we are interested? If so, cannot the same question be asked about the second judgment of coherence? A foundationalism of some sort is needed. Or consider BonJour's a priori theorem that extratheoretical causation is the best explanation of coherence. If this is theorem, its truth is not know deductively; it is known by a prior insight into, among other things, the relation between any set of non-random beliefs and any non-random world. Deduction itself ultimately turns on a direct insight into the logical relation between premises and conclusion. If we accept such acts of direct insight into conceptual data, on what grounds do we deny the equally commonplace occurrences of direct insight into data of sense? 
It will be pointed out that, unlike the earlier reference to the law of inverse squares, the geometrical example given above involved knowledge which was, in some sense, a priori, and that the second example involved conceptual or propositional data, that is, the contents of an act of understanding; whereas our puzzle about seeing a red patch involved neither. (Of course it is easy to produce cognitions which are quite simple and which are unquestionably empirical. Consider a pattern of colors: e.g., red; green; red red; green green; red red red; green green __ ?_..) But is one really prepared to say that one acquired such a priori geometrical knowledge quite independently of data which instantiates its truth, or that one could see that and how it was true of particular items of data without having some insight into the nature of the data itself? ${ }^{3}$

In the case of conceptual data, as has already been noted, what is relevant to our problem is the potential such hypotheses have for further insights into their logical relations; in this respect they are like the example from geometrical and physics. And, again, if we can achieve a justified true hypothesis in these instances, why not in the case of knowing there is a red patch, however banal the insight may be? The alternative is to hold that in such simple cases knowing is just taking a look; but if so, it is difficult to see why anything more would be required in the more complex cases, as it obviously is.

3 Knowing there is a red patch does seem somehow different from knowing something about the patch, especially a necessary geometrical truth about it. Unlike the so-called secondary qualities, primary qualities seem somehow uncapturable by insight. One just senses them, imagines them, conceives them as the referents of mass terms having scattered but concrete location (as "pieces of red"), or one links them with same as or same color as. The red qualia itself seems to elude conceptualization. It is as though the concept red patch must consist at least partly of a red sensum if it is to have any content at all, whereas the concept foul or perhaps even four sided need not be constituted by an image and would never (except by British empiricists) be literally identified with an image. Space does not permit an adecuate discussion of this difficulty, but surely it would be a serious problem for any theory of empirical knowledge if such data proved to be intrinsically unintelligible. 
There is no appeal here to "self-verifying" beliefs or hypotheses. If one is preternaturally dull-witted, nothing prevents one's understanding the hypothesis There is a red patch at the same time one is seeing a red patch, but failing to grasp that the latter makes the former true. It is true that one could not have learned the meaning of 'red patch' without observing red patches under appropriate circumstances; nevertheless, 'red patch' means any red patch, not just those one happened to observe when learning the expression, among which the present red patch may not have appeared. To relate the proposition which is understood to the data which is sensed (or to propositions understood in a fragmented way) requires grasping the intelligibility of the data in the data. This is not the sort of foundationalism to which BonJour objects; it is a sort of foundationalism which he apparently has not considered.

To summarize, BonJour is right in insisting that justification of an empirical "belief" (hypothesis) cannot simply be a matter of looking at the data to "see" if the "belief" (hypothesis) is true. Believing and hypothesizing are act of intelligence (both, for example, require at least one general term), but seeing is an act of sense. Part of the problem is to promote the latter to the status of the former. This last operation is crucial; for without it there is no possibility of relating the hypothesis to the data intelligibly, and with it no hypothesis is needed in the most fundamental case, as we shall see below. We need only be concerned in what follows with this most fundamental case.

\section{II.2.: Taking Cognitive Possession as Justifying an Insight into the Data}

Granted we can catch on to something intrinsic to the data itself, and that this is essential, in one way or another, to all empirical knowledge, how are such insights to be justified? Now, justification of an insight cannot lie in experiencing the data or having the insight, for one has already done that and doing it again would not be helpful. Neither, obviously, can it be achieved by recourse to other insights into other data (of whatever sort), for these in turn raise the same issue; nor can it be a matter of knowing we are experiencing the data or having the insight for, besides being un- 
necessary, such knowledge would also require justification. This is where the issue was left in the Theaetetus.

But why is it that we are interested in confronting the data, inventing hypotheses, having insights, and worrying about whether they are justified? One may have ulterior motives, of course, (say, to publish even though one will perish), but the motive that drives and guides the cognitional process intrinsically is just the desire to know, Aristotle's "wonder." It is because we want to "scratch" this "itch," to borrow a homely expression from Wittgenstein, that we are not content merely to experience the data but go on to hypothesize about its intelligibility and seek to determine whether the hypothesis is true. We proceed in this way because we want what we are after with a desire which is intrinsically intelligent and normative, although in itself this motive does not constitute knowing anything.

If the reader rejects this view, let him ask himself whether he rejects it because he has never had the experience of knowing or trying to know something; or because, although he has had such experiences, he remained utterly without curiosity about what constituted such efforts as instances of knowing or trying to know; or because, having become intellectually engaged, he sought no insights and proposed no hypotheses; or because, having gotten to that point, he had no interest at all in whether the insight or hypothesis was correct? If the answer to any of these questions is 'Yes', his position surely loses all plausibility even in his own eyes. If, on the contrary, his view seems plausible to him because it met these criteria, let him ask himself whether the operative sense of "because" indicates something which at each stage was conscious and normative - not conscious merely as an object of consciousness or normative in the sense of a nomograph which intelligence consults, but intrinsically conscious in the sense described above (1.6) and intrinsically normative in sense not unlike that in which thirst is said to be normative of what counts as drink.

The problem is not whether there is such a normative intellectual dynamic - the reader may easily determine that for herself, for to raise the question is ipso facto to answer it in the affirmative. The problem is to appropriate its significance for justification and, of course, to meet its demands on important issues. The desire to 
know what is really the case, and the operations it generates for its satisfaction, are not "practices" in the sense of a convention, nor are they a motive and way of doing things by which we just happen to be ineluctably bound. They are the substance and sense of the cognitional enterprise, and would be the substance and sense of any attempt to show that they are not. They are "where the spade turns," to quote Wittgenstien again.

If this is correct, then justification can be nothing other than the constitutively conscious satisfaction of this desire. We have been looking for justification in the wrong place. We have been looking at what needs to be justified and ignoring the normativity of the need itself. The intellectual satisfaction is the justification, for a rationally normative inquiry cannot but be consciously terminated as successful when the demands intrinsic to that inquiry have been fully satisfied, that is, when nothing further remains to inquire about. For rejection or revision could only be a response to such unresolved questions.

In the (distressingly rare and usually rather trivial) cases when this occurs one says that there remain no unresolved questions relevant to the precise issue at hand. Is one not prepared to say this? Then quite evidently one's cognitive project is not yet consummated, and if one is intellectually authentic one will go on inquiring and trying to understand. "My answer is correct because it terminates my questioning - that is what correct answers do." But is it really the answer or does it only seem so to me? Well, am I intellectually satisfied or am I not? If not, I should reserve judgment while I examine the matter further. If I am, my skeptical question is a futile attempt at self-deception. But perhaps my inquiry is immature, not sufficiently thorough and rigorous. To consider this possibility is to confirm the norm and to present one's self with the remedy.

\section{II.3. Objections: Subjectivity, Vacuity, Futility}

It will be vehemently objected that this account of justification is both subjective and vacuous. With regard to the first objection it may be pointed out that the norm-the intellectual need - to which the theory alludes is the very one which is motivating the objec- 
tion. Is the objector's objection subjective because it is the result of his authentic desire to get at the truth, to reject all fudging? Does he himself ever act on that motive? If he succeeds, will he know no more about what is really the case than if he had failed? If he thinks he has not succeeded, will that not be because he realizes there are further, relevant questions which need satisfactory answers?

To be in the grip of this motive is definitive of objectivity on the part of the epistemic subject, just as, correlatively, what is the case is definitive of objectivity with regard to truth. Again, this will become evident when the claim is attacked; for the attack will attempt to show at just what stage in the process described above my argument went astray, and will implicitly appeal to my sense that any such offence runs counter to the intellectual desire I am, or ought to be, trying to satisfy. It will argue that there are relevant (not merely germane) issues which remain to be addressed or that the insights proposed as solutions are not satisfactory, and it will return to the problem to formulate those further questions and find more satisfactory insights. Thus every attempt to refute the proposed theory will implicitly appeal to its truth, and the more vigorously the refutation is argued, the more illuminatingly will it refute itself. In the same way, to demand that the theory itself be justified is to respond to the normative motive which that theory asserts to be controlling, and to be convinced that the theory cannot be justified is just to be conscious that it leaves that normative desire unsatisfied.

Is this account of empirical knowledge vacuous? Although the normativities invoked are constitutively conscious in the cognitional operations, they can be explicitly formulated and thus made objects of consciousness. One is required to attend carefully, inquire intelligently, ask all the necessary questions, and accept only fully satisfactory insights as answers. One is urged to remain authentically committed to this intellectual enterprise while he is engaged in it and to be aware when he ceases to be engaged in it.

The ways these motives and operations produce science are pretty well known. But even if one provided formulae that could be applied in every case by a clerk, the resulting knowledge would be only a clerk's knowledge. For if one wished to know anything it would still be necessary to care intellectually about whether the 
algorithm was correct, to inquire whether it was, to catch on about why it works, and arrive at a fully satisfactory understanding. The appeal is to the normative motives and operations which are fundamental both to inventing such procedures and to applying them to specific cases. But if the norms and motives are not already operative in one's conscious life the attempt to formulate them explicitly will, of course, be futile; for one will understand neither the formulation nor what is being formulated.

Those (many, I fear) who remain unconvinced will perhaps come to view this suggestion more sympathetically if they ask themselves once again what else justification could be. For it surely cannot be any hypothesis, insight, judgment, or percept, nor, indeed, the content or object of any epistemic act whatever; for these either require justification themselves or require an intellectual act which requires justification. And yet justification must be consciously, essentially, and normatively related to all of them.

It will also be objected that this account leaves us exactly where we were. How else would such an insight into the sensum be found to be satisfactory except by reference to the raw sensum? But it is not a question of referring to, that is, looking at, the raw data. We have already done that. Beyond experiencing, we are epistemically connected with the present sensum at the level of intelligence by our wonder, by our hankering to know. The insight into the data is both the response to and the satisfaction of that curiosity about the data.

And note that, although it is perfectly possible to know that one's intellectual hankering is satisfied by the insight, it is not necessary to have such knowledge. The act of insight into the data and the correlative normative satisfaction already comprise one, complete, constitutively conscious act of knowing; and knowing that it does would constitute another such complete act of knowing.

On this theory, justification turns out to provide both less and more than we had been expecting: less, because it does not describe types of arguments or evidence which would justify kinds of hypotheses provided we understood the arguments and evidence correctly; more, because it explains how it is that we can be more or less certain we have such correct understanding. The explanation is neither mysterious nor recondite. Indeed, it probably strikes 
the reader as an anticlimax. It describes a normative dynamic so familiar that one has perhaps never bothered to reflect upon it: a normativity which is at first consciously operative but implicit, grows more sophisticated and nuanced as we become intellectually mature and more familiar with the subject matter, but becomes explicit only with the kind philosophical reflection we have been engaged in.

\section{II.4. Getting It Right about Getting It Wrong}

Finally, the proposed theory does not provide a error-proof algorithm; for to be error-proof would be to be literally foolproof, and we are all foolish from time to time. Of course that is a point in the theory's favor, for any epistemological theory must allow for, and indeed explain, the fact that we do make mistakes, that we are sometimes intellectually satisfied, it would seem, when we ought not to be. The present account does not solve Plato's puzzle about how we can be wrong, but it does clarify it. We err because the vigor of our intellectual curiosity, the pure, disinterested desire to know, fails, and when it fails our awareness that it is failing eventually fails with it.

When one is a fully conscious intellectual player she cannot err (although she must very often withhold judgment); when one is completely without intellectual interests the question of being justified or not being justified does not arise, for then she is not a cognitive player at all. It is when one is not fully in one the state nor the other that she inquires inadequately and is no longer conscious that she does. The problem cannot be further pursued here (it troubles every plausible epistemology), but the present suggestion, I submit, at least accurately describes what happens when one makes a mistake.

\section{II.5. Conclusion: Seeing Red with the Man-in-the-Street}

Recall the perplexity of our non-philosopher asked to justify his belief that he is experiencing a red sensum at the very instant he is in fact experiencing it. He was not at all perplexed about whether he was seeing what he was seeing; he was perplexed about 
the philosopher's question. What more could the philosopher want, it being granted all around that there is a red patch before his consciousness? It is now clear what the philosopher was, or should have been, after: he wanted to know whether the person he was addressing understood what 'seeing a red patch' means and was intellectually satisfied with his insight that the data before his consciousness was an instance of one.

It was because the inquiry was so banal and because a fully satisfactory insight posed no perceptible difficulty that the perplexity arose. Of course our man-in-the street might have insisted that just seeing the red patch, or seeing the red patch while understanding the expression "There is a red patch", was sufficient for knowing it. In that case he either would not have been justified in believing there was a red patch or would have misunderstood how he knew what he knew, in the same way the foundationalist with whom both BonJour and I disagree misunderstands how he knows what he knows.

\section{References}

BonJour, Laurence. The Structure of Empirical Knowledge. Cambridge: Harvard University Press, 1988.

Lonergan, Bernard, J.F.. Insight: A Study of Human Understanding, 5th Ed., Collected Works of Bernard Lonergan. Toronto: University of Toronto Press, 1992. 